\title{
Chinese Characteristics and International Standards: Study on Evaluation System of Scientific and Technological Innovation Capacity of "Double First-Class" Universities
}

\author{
Xiaoping Huang ${ }^{1} \&$ Yang-Zi Chen ${ }^{2}$ \\ ${ }^{1}$ Institute of Education Research, Jiangxi Normal University, Nanchang, China \\ ${ }^{2}$ Department of Air transport, Shanghai Civil Aviation College, Shanghai, China \\ Correspondence: Huang Xiaoping, Institute of Education Research, Jiangxi Normal University, 330022, China. \\ Tel: 1-887-917-0973. E-mail: hxp832007@126.com
}

Received: September 10, 2019

Accepted: October 15, 2019 Online Published: November 5, 2019

doi:10.5539/hes.v9n4p189

URL: https://doi.org/10.5539/hes.v9n4p189

\begin{abstract}
In the construction of "Double First-Class" universities, how to establish an evaluation system of universities' scientific and technological innovation capacity with Chinese characteristics and international standards will determine the direction and level of improvement of Chinese university's technological innovation capacity. The system of scientific and technological innovation in university is a complex system, and the existing evaluation index and evaluation system may be difficult to meet the actual needs of the national construction of "Double First-Class" universities in the new situation, so the evaluation index should be a breakthrough and innovation. This paper probes into the existing problems in the evaluation system of scientific research in China, systematically investigate the common and different features of scientific research evaluation in Britain, America, France and Australia, puts forward the new connotation of the structure dimension of Chinese universities' scientific and technological innovation capacity, and points out the basic criterion of constructing the evaluation system of university scientific and technological innovation capacity: First, design of indicators should reflect the development trend of the world, and reflect the cultural characteristics and historical background of Chinese universities. Second, it is necessary to according to the "world standard", reflect the value orientation and practice standard of Chinese university construction. Third, taking differentiated design and establishing a classification evaluation standard. Fourth, the evaluative dimension should reflect the diversification of evaluation content, especially considering to optimize overall scientific research ecology.
\end{abstract}

Keywords: "Double First-Class" University, Scientific and Technological Innovation Capacity, Evaluation System, International Standard

\section{Quote}

Scientific and technological innovation capacity of university mainly include the input of scientific and technological innovation and output capacity, its main objectives are constructing a scientific evaluation system to reflect the output capacity of scientific and technological. Thus, the output capacity of scientific and technological is an important measure of the evaluation of scientific and technological innovation capacity in universities. However, the existing scientific and technological innovation capacity of universities evaluation indicators and system may be difficult to meet the actual needs of national construction of "Double First-Class" universities under the new situation, to meet needs of constructing "Double First-Class" universities in China, evaluation system should have breakthrough, innovation and development, and some indicators need to be rebuilt.

Evaluation of scientific and technological innovation capacity in universities is a complex system, in order to evaluation comprehensively, objectively and reasonably, it is necessary to have a series of evaluation indexes to reflect its internal structure. Therefore, the evaluation indicators should not only constitute a complete scientific system but also fully reflect the current situation and actual characteristics of the scientific and technological innovation capacity of Chinese universities, especially the local characteristics of the "First-Class" universities. That is, "Double First-Class" universities should be "World-Class universities" with "characteristics", especially in the process of building "First-Class Disciplines" and "World-Class Universities". The design of the scientific 
evaluation system is helpful to clarify the development direction of university construction and thus to promote the overall scientific and technological innovation capacity of "Double First-Class" universities in China. Thus, the "Double First-Class" university scientific and technological innovation capacity evaluation system proposed in this paper mainly refers to: under the construction of "Double First-Class" university national strategy background, inspects our country scientific research appraisal development reality and the main question. The international standard of scientific research evaluation in developed countries is used for reference, which provides a reference framework for evaluation of scientific and technological innovation capacity of "Double First-Class" universities in China. For the establishment of Chinese characteristics and international standards "Double First-Class" university scientific research evaluation to provide development ideas.

\section{Current Situation of Evaluation System of University Scientific Research in China under the Background of "Double First-Class"}

The overall goal of "Double First-Class" construction in the new period puts forward new challenges and new requirements for improving the scientific and technological innovation capacity of Chinese universities. However, there are some contradictions between the development of the evaluation system of university scientific research in China and the overall goal of "Double First-Class" construction, as follows

\subsection{The "Administrative" Characteristics of Scientific Research Evaluation Institutions in Universities}

At present, the mode of university governance in China is dominated by government administration, which urges the organization and operation of university scientific research evaluation activities to be carried out inevitably according to traditional "administrative management mode". As a result, the evaluation institutions of university scientific research evaluation activities also take the science and technology management department under the government's supervision as the main body, the private intermediary appraisal organization or the individual, the organization as the supplementary condition. For example, the Ministry of Education (formerly the State Education Commission) published the ranking of 14 universities in China for the first time in the overseas edition: people's Daily in 1992. Since then, the first 100 universities published in 2002 and the top 50 universities in patent applications in 2003 have been published jointly with semiofficial institutions. Of course, this situation brings many problems and drawbacks. For example, the top-down scientific research management model is difficult to mobilize the enthusiasm and enthusiasm of the universities to participate in the evaluation, the prevalence of the bad ethos such as officialdom and the "Matthew effect", and the administrative departments playing a role in each other. Therefore, with the scientific research management system of the government in charge, it is also "administrative" in the evaluation of the scientific and technological innovation ability of the university, which is contradictory to a certain extent with the current "Double First-Class" construction.

Construction of "Double First-Class" embodies double goals of "World-Class University" and "First-Class Discipline", both of which pursue the orientation and goal of "World First-Class", which is embodied in the evaluation of university scientific research. The "Credibility" of the evaluation system and evaluation activities was emphasized. Such "Credibility" can be recognized and recognized internationally, so that evaluation systems, evaluation criteria, indicators and methods should to a large extent be guided by "Universal and Worldwide Values". The concrete performance is to pursue the academic autonomy and freedom of universities, and pay more attention to the evaluation results with credibility, science and objectivity. Only through credible and true evaluation data and information (that is, the reliability and validity standard of evaluation results), can universities better find their own gaps, and refer to the international "First-Class universities" and "First-Class discipline" construction standards. Combined with the development characteristics of Chinese universities, enhance their scientific research capabilities and other comprehensive strength. Therefore, the construction of "Double First-Class" requires that the evaluation institution of scientific research evaluation in China should be independent and authoritative step by step, and realize the separation of "Management, Running and Evaluation" in the management system of scientific research. The establishment of an authoritative, independent and unofficial third-party evaluation institution will help to improve the efficiency of the evaluation of university scientific research in China and ensure the credibility and validity of the evaluation results. It is also conducive to readjusting and promoting the "Double First-Class"construction in achieving the"three-step"goal of university scientific research management one by one.

\subsection{The Single of Scientific Evaluation Criteria and Evaluation Methods in Universities}

In China, standard of scientific research evaluation activities in universities usually adopts the assessment model of "single" and "unified", it is difficult to type on the different schools,disciplines and assessment of characteristics scientific, as a basis for evaluation is always the expected target value and domestic university 
discipline "norm” (“985” "211” universities and key subjects) (Zhang, 2016). When evaluating university scientific research innovation ability, we adopt a single quantitative evaluation method, ignore the citation rate of papers and peer expert evaluation, it will cause heavy quantity and light quality of scientific research evaluation. This kind of scientific research evaluation method and evaluation standard is "simple unity", "unified standard" and "Double First-Class" construction target existing contradiction and conflict. It has a specific performance: the "Double First-Class" construction plan should be pointed out that "first-class universities"in the global and "first-class discipline" in the international as the evaluation of our university construction level and reference, which requires the ability of scientific research evaluation in our university should use international scientific evaluation standards as the "reference target". As the White House Science and technology consultant Above pointed out that the construction of a first-class university only through the use of internationally recognized standards as a measure, the university could be a first-class university. Meanwhile, the first-class standard direction can not deviate from the track or act alone.

\subsection{Excessive Quantification of University Research Evaluation Indicators}

University research evaluation indicators in China are generally divided into three categories: university research input indicators, achievement output and transformation indicators and research basic indicators. Among them, the main indicators of university scientific research input are funds and human resources, such as the proportion of doctoral teachers, the total amount of research funding and so on. The indicators of achievement output and transformation generally include academic papers, patents, awards of science and technology, achievement transformation and talents cultivated and so on, academic papers and books published, number of citations, patent application and authorization number, received awards of science and technology, technology transfer, real income and number of personnel awarded are mainly the reference indicators; research basic indicators include the human resources, material conditions, scientific research base and academic exchanges in four categories, such the number of teachers and graduate students, Instrument and equipment and library conditions, the number of key disciplines and the frequency of international exchanges and cooperation as the specific indicators. It is found that the existing university scientific indicators more emphasis on quantitative indicators of the above three categories, others are more refined as the number of SCI papers, the number of ESI subjects and ranking number, the number of domestic and foreign patents, the number of National Natural Science Fund and other major research projects, the amount of research funding input, the number of the national winners, Chang Jiang Scholars and thousands of people plan number, the number of academicians and other indicators (Xiang, 2016). As for in the university the attention of the cultivated quality of innovative talents, academic reputation, achievements of research, social and economic influence, the patent conversion rate and other "quality indicators" are not high, the lack of operating methods to quantify the "quality indicators" in the actual assessment. In addition, the above three categories of scientific research evaluation indicators cannot fully highlight and embody the common characteristics and internal development rules of "first-class disciplines" and "first-class universities". Therefore, we think that we can learn from the design concept of first-class university research evaluation system in Britain, America, France Australia and other developed country,the practical experience of first-class universities' development, the common and different characteristics of research evaluation system reflects the scientific, selected key indicators to reflect the science and technology innovation ability of "Double First-class" university, in order to achieve the "convergence" and "dialogue" with the evaluation indicators of the developed countries.

\section{Characteristics of Evaluation System of Scientific and Technological Innovation Capability of World Class Universities-Taking Britain, United States, France and Australia as Examples}

The United Kingdom, the United States, France and Australia are the most representative developed countries with the largest number of world-class universities. These evaluation systems of science and technology evaluation systems play a guiding role in the evaluation system of university science and technology innovation capability. When the developed countries evaluate universities scientific and technological innovation capacity, they are usually more concerned about the four main objectives: output of scientific research, quality of scientific research, impact on other researchers, and whether creative technology bring benefits to the economy and society or not (Aldo \& Ben, 2003). The research evaluation system in these countries mainly embodies the following four common features: The first is to use evaluation purpose as its main evaluation orientation, and to establish the mode of resource allocation, regarding the national policy or law as a guide to action, the establishment of international standards for scientific research evaluation. The second is based on the national policy or law as a guide to action, to establish international standards of scientific research evaluation. The third is the pursuit of "quantity" but more emphasis on "quality", focusing on the realization of "benefit". The forth is to establish a multivariate evaluation method based on the evaluation of the subject category (Huang \& Chen, 
2017).

It should be pointed out that although there are common features in the evaluation system of scientific and technological innovation capacity, different countries follow different traditional history and institutional culture. The evaluation system of universities scientific and technological innovation capacity also presents the development characteristics of "dissimilarity" and "harmonious yet different", which provides various possibilities for the distinctive development, diversity and richness of universities in various countries.Characteristics of first-class university reflect the stand of "local characteristics" and "international standards" that each country constructs in their own scientific research evaluation system and also reflect the coordination and unity of "individuality development and common development" in the international multivariate symbiosis development pattern of higher education.

\subsection{Based on "Function Division", Selecting Multilateral Evaluation Mechanism}

Internationally, the evaluation function of government evaluation bodies in Britain, The United States, France and Australia has a certain degree of difference between the four countries. The British, French and Australian governments play a major role in the universities' research evaluation activities, indirectly participate in the evaluation process, control the overall development trend of universities' research evaluation activities and undertake responsibilities more broadly. As the Higher Education Funding Council (HEFC) is the semiofficial scientific research evaluation institutions located between the government and the University, but it is still the main research commissioned by the British government allocated funds, formulate detailed funding methods and processes, clear university research funding should assume obligations and responsibilities, and the system level of Teaching and Research Universities of England evaluation and other information such as the British government transferring to the University, setting up quality assessment working group, the fund supervision and verification working group, information consulting and service working group and other types of institutions respectively in its internal to carry out the evaluation of scientific research, appropriation of funds and so on (Kan, 2010).

The French research and higher education assessment agency (AERES) is the official scientific evaluation mechanism led by national government, it evaluates University of France's overall level of scientific research and specific academic achievements, mainly responsible for planning and evaluation of research strategy, selecting evaluation team members and distributed evaluation results, etc., and directly participated in activities of the whole university research evaluation process. The Australian Research Council (ARC) is a semiofficial nature of scientific evaluation mechanism, mainly responsible for the organization and implementation of specific research projects, improve and promote the overall development of the scientific research system, and by setting up the research assessment working group, peer assessment working group and supervision committee and other affiliated institutions to ensure the effectiveness and rationality of the whole process of scientific research evaluation.

However, the evaluation subject of the authority and typical is non-official and non-profit scientific research institutions--Evaluation Research Committee of National Science (NRC), it worked by the United States government investment agency research and assessment, mainly responsible for quality assessment and the level of research universities in the university.it works for a US Ph.D. research project ranking about every ten years. It is not difficult to find that the responsibilities of the research evaluation institutions in Britain, America, France and Australia are different, the scope of the work involved in it is not the same, and the nature of the evaluation institutions is also different. Therefore, different countries selected for the development of their national condition such as official, semiofficial or unofficial and so on. The evaluation of scientific research institutions although influenced by government intervention, but overall still maintain the relative independence of the subjects of evaluation, become the bridge and link between the university and society, the connection of government and enterprise. The main body, as far as possible to achieve the greatest degree of security research and evaluation activities of the college of justice, standardization and objectivity, to carry out scientific research evaluation activities based on "university autonomy, supplemented by indirect government adjustment".

\subsection{Taking "International Standard” as the Benchmark, Screen Their Own "Characteristic”Indicators}

The selection and determination of scientific research evaluation indicators of universities in various countries should not only be based on the national conditions, but should also refer to the international standard. The scientific and reasonable choice of scientific research evaluation is closely related to the correct reflection of the development of the scientific research of university. The evaluation indicators of the excellent scientific research evaluation framework REF of the university, newly developed by the UK, are divided into achievement quality, achievement influence and research environment. It emphasizes the quality of research achievements and 
focuses on the economic, ecological benefits and other influence indicators of research achievements (Ryuohtani et al., 2013).

Scientific research evaluation indicators in the United States mainly include scientific research projects, student participation and research achievements, the diversity of subjects in the educational environment (National Research Council, 2004). For example, the first-grade index of "scientific research project" includes the specific indexes, such as the publication volume and citation rate of papers and publications, the basic information of scientific research personnel, the amount of scientific research funds obtained in previous years, etc. "Student participation and research results" include the basic information and level of students, graduation rate and employment rate, the proportion of students who obtained the full scholarship, etc. "The diversity of subjects in the educational environment" includes the diversity of ethnic groups of teachers and students, the proportion of female teachers and students and others.

The scientific research evaluation indicators in France can be generally divided into scientific research activities, scientific research environment and scientific research application, and they respectively play the distinctive functions in the scientific research evaluation activities in universities (Documentation Francoise). However, the excellence research ERA scientific research evaluation system in Australia is classified from four dimensions, including research quality, scientific research quantity and activity, the application of scientific research and recognition. Especially, it focuses on the quality of scientific research achievements and international recognized indicators (Australian Research Council, 2012).

In conclusion, specific indicators of Britain, America, France and Australia have their own characteristics and emphasis. Scientific research evaluation indicators in Britain and Australia focus on evaluation of the quality of research achievements. They give a higher proportion of weight on the quality of achievements and emphasize the output of high-quality scientific research achievements. The United States and France focus on evaluation of the application indicators of scientific research environment and scientific research achievements and pursue a good research atmosphere, outstanding scientific research staff and the available scientific research achievements that bring high benefit to the country, society, economy, culture and other fields. Although these indicators seem different, they also have common features, such as scientific research evaluation systems of universities in all countries pay great attention to the quality of scientific research achievements, focus on study of benefits of output in social, economic, ecological and other fields. Besides, they carry out the international comparison of indicator systems in different countries, gradually adjust and revise the deficiencies of their scientific research evaluation indicator system based on multiple disciplines and finally construct the indicator system which cannot only meet the actual requirements of the domestic scientific research development but is also in line with international standards.

\subsection{Taking “Precise Specification” as Direction, Planning Various Development Strategies}

The specific operation process of scientific research evaluation in all countries is becoming normative and precise. However, they also have small differences. The process of scientific research evaluation in British universities is clear and definite, mainly including the division of evaluation unit, the submission of scientific research evaluation data of universities, the evaluation of expert committee on all materials and the distribution of the evaluation results (Sue, 2015). Due to the diversity of evaluation institutions and evaluation standards, the evaluation process in the United States is more complicated than that in Britain. For example, OTA official scientific research evaluation pays attention to invite authoritative experts and scholars in all fields at home and abroad to evaluate scientific research materials repeatedly (Chen, 2007). However, except the Peer expert evaluation, the scientific research evaluation in Berkeley university also stressed the self-assessment results of the participating units (http://Teaching.Berkeley.edu/academic-programs). The process of Australia's ERA scientific research evaluation mainly includes the following steps. Firstly, the university candidates submit assessment materials and the research quality evaluation system automatically classified materials according to subject codes. Secondly, the research evaluation committee evaluates the classified materials. Thirdly, experts of the research evaluation committee repeatedly made evaluation according to the ERA evaluation criteria. Fourthly, the research evaluation committee determines and announces the final evaluation results through consultation and discussion based on the preliminary scoring in the third step. It is obvious that the process of Australia's ERA scientific research evaluation system is more advanced, standardized and convenient. It adopts the automatic management mode of the computer system, so it saves a lot of cost and time, and further improves the accuracy of the evaluation results (see www.arc.gov.au/e).

Meanwhile, medium- and long-term development strategy of scientific research evaluation in all countries will be constantly updated and changed due to the actual operation process. Therefore, the timely adjustment of the 
evaluation cycle and evaluation content of scientific research based the dynamic development of medium- and long-term strategic planning is necessary. It also causes the differences and volatility of Britain, the United States, France, Australia and Australia in the evaluation content and evaluation cycle.

In the evaluation cycle, the seven scientific research evaluation activities in the UK were 1986, 1989, 1992, 1992, $1992,2008,2014$, respectively. The interval is gradually extended from a three-year cycle to four or five years or even a six-or seven-year cycle. The extension of scientific research evaluation period depends more on improvement of evaluation content, evaluation process and evaluation methods in its medium and long-term development strategy. The medium and long-term development strategy of British scientific research evaluation activities mainly focuses on the systematic planning of scientific research policies, plans, projects, institutions and so on(Tony \& Daniel, 2014). Evaluation cycles in France and Australia are similar to those in the United Kingdom, which range from four to five years, compared with shorter intervals in the United States (Australian Research Council, 2012).

It is worth noting that the United States and France are more similar in the medium and long-term development strategy of scientific research evaluation activities, and pay attention to the evaluation of scientific research institutions and scientific research personnel. Australia places more emphasis on evaluating research policies and specific research projects. In addition, in scientific research evaluation period, the United Kingdom, the United States, France use prior, interim, post-systematic and continuous evaluation interval, actively grasp the overall development of evaluation system. Australia emphasizes interim adjustment and revision evaluation of scientific research system process and the timely feedback evaluation after the completion.

Therefore, Britain, the United States, France and Australia in scientific research evaluation activities in the actual operation process in order to continuously reduce the error of evaluation results, improve the reliability and validity of evaluation results. A lot of efforts and practical exploration have been made in adjusting and optimizing the evaluation time.

\subsection{Take "The Object of Evaluation" As the Main Body, Playing Different Functions of Evaluation}

In general, the results of scientific research evaluation activities in the university have the role of identification, motivation and guidance, diagnosis and adjustment, supervision and management. Among them, the function of identification refers to the confirmation of the scientific research evaluation and estimate whether the evaluation objects meet the requirements, the level of strengths and weaknesses, the degree of differentiation, the order and qualification, and other level of ability of the actual value, identification is the basic function of scientific research evaluation. The implementation of other functions is based on identification, it can also help the subject of evaluation find out the distance between itself and the target value of scientific research timely and accurately, adjust and amend their own direction of development; The function of motivation and guidance refers to the ability of scientific research evaluation which can guide and motivate the evaluation objects toward the target value of scientific research. It depends on the orientation of the evaluation criteria and can stimulate and maintain the potential ability of the evaluation object and internal motivation, arouse the evaluated objects 'enthusiasm and initiative of the work, accordingly, we strive to achieve the desired goal value of scientific research. Diagnosis and adjustment refers to the scientific research evaluation in university make a judgment of the results and benefits, contradictions and problems of scientific research and in view of various problems, primary and secondary contradictions in this scientific research activities, tackle the problems timely and the level of amendment, in addition, it has special significance and function for continuously improving the quality of scientific research in university and achieving the goal of scientific research management. Supervision and management means that university scientific research evaluation play the role of detection and supervision for appraisal objects, by comparing the appraised object with the expected goal value and verifies whether it meets the expected goal value and how deep can be reached, then it strive to promote them to achieve the desired objective smoothly and do more behavior of regulating for it.

Due to the different purposes of the use of evaluation results in different countries, like Britain, the United States, France and Australia, the effectiveness of scientific research and their ability at university to be different. The main objective of the final outcome of the UK scientific research appraisal is to use the assessment results directly to determine the allocation of research funding to universities. The UK Higher Education Fund Board, in combination with the grading of evaluation results, the number of university researchers and regions Allocation of funds using a variety of capital allocation methods, giving four times as much funding in the highest level of assessment university as in the lower level university, British universities can use scientific research funding freely, thus scientific evaluation play its basic role. The main objective of the evaluation of university evaluation in scientific research evaluation activities in the United States is to diagnose and regulate. Specifically, it helps 
American universities to determine its development direction and improvement measures as a whole and helps all kinds of level of management apartments and scientific researchers to recognize their own performance, then adopt remedial measures and adjustment measures to make up for the deficiency and the development advantages within the university could be revealed. The French research evaluation system and the Department of Higher Education Evaluation AERES regard the evaluation results as the principles of scientific research funding support, the main goal is to use the continuous improvement of scientific evaluation system to build French university as the main body and center of scientific research gradually, to strengthen the French universities' International reputation and competitiveness effectively. So that its research evaluation mainly demonstrated the effectiveness and ability of motivation and guidance. While Australia's results of evaluation are not directly linked with the research funding, the results only as reference to measure the research grants received by universities. Australia believes that if the evaluation results linked to scientific research funding directly will lead to vicious competition among researchers, so that the focus on target of evaluation is assessing the performance of various scientific research work and scientific research personnel within the university to help them develop scientific and rational development strategies of scientific research, its scientific research evaluation not only has the basic role of recognition and identification that similar to British ,but also has the functions of supervision and management.Therefore, the scientific research evaluation of universities in different countries base on the different evaluation objectives and take all kinds of specific evaluation objects as the key points and optimizes the scientific evaluation system of universities to an extreme in various countries.

Table 1. Comparison of universities' scientific research evaluation system in Britain, America, France and Australia (Aldo \& Ben, 2003)

\begin{tabular}{|c|c|c|c|c|}
\hline Country & Britain & America & France & Australia \\
\hline $\begin{array}{l}\text { Evaluation } \\
\text { institution }\end{array}$ & $\begin{array}{l}\text { Higher Education Funding } \\
\text { Council for England HEFCE }\end{array}$ & $\begin{array}{l}\text { National Research } \\
\text { Council }\end{array}$ & $\begin{array}{l}\text { Agence d'évaluation de la } \\
\text { recherche et de } \\
\text { l'en-seignement supérieur }\end{array}$ & $\begin{array}{l}\text { Australian Research } \\
\text { Council }\end{array}$ \\
\hline $\begin{array}{l}\text { Evaluation } \\
\text { organization }\end{array}$ & REF & $\mathrm{NRC}$ & 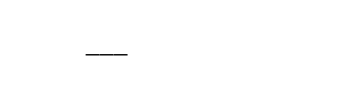 & ERA \\
\hline $\begin{array}{l}\text { Evaluation } \\
\text { purpose }\end{array}$ & $\begin{array}{l}\text { Distribution of scientific } \\
\text { research funds }\end{array}$ & $\begin{array}{l}\text { Determining university } \\
\text { development direction } \\
\text { and improvement } \\
\text { measures }\end{array}$ & $\begin{array}{l}\text { building universities } \\
\text { gradually into the main } \\
\text { body and center of scientific } \\
\text { research }\end{array}$ & $\begin{array}{l}\text { Helping universities } \\
\text { to formulate the } \\
\text { development } \\
\text { strategy of rational } \\
\text { scientific research }\end{array}$ \\
\hline Evaluation content & $\begin{array}{l}\text { The quality of achievement, } \\
\text { the influence of achievement } \\
\text { and research environment }\end{array}$ & $\begin{array}{l}\text { Scientific research } \\
\text { projects, student } \\
\text { participation and } \\
\text { research results, the } \\
\text { diversity of subjects in } \\
\text { the educational } \\
\text { environment }\end{array}$ & $\begin{array}{l}\text { Scientific research activity, } \\
\text { research environment and } \\
\text { scientific research } \\
\text { application }\end{array}$ & $\begin{array}{l}\text { Research quality, } \\
\text { quantity of scientific } \\
\text { research and activity, } \\
\text { scientific research } \\
\text { application and } \\
\text { recognition }\end{array}$ \\
\hline $\begin{array}{l}\text { evaluation } \\
\text { standard }\end{array}$ & Four levels & Five levels & Opinions of evaluation & Five levels \\
\hline $\begin{array}{l}\text { Evaluation } \\
\text { method }\end{array}$ & $\begin{array}{l}\text { Bibliometric indicators, peer } \\
\text { evaluation }\end{array}$ & $\begin{array}{l}\text { regression analysis, } \\
\text { Bibliometric } \\
\text { indicators, peer } \\
\text { evaluation }\end{array}$ & $\begin{array}{l}\text { Bibliometric } \\
\text { peer evaluation }\end{array}$ & $\begin{array}{l}\text { Bibliometric } \\
\text { indicators, } \\
\text { evaluation }\end{array}$ \\
\hline $\begin{array}{l}\text { Evaluation } \\
\text { process }\end{array}$ & Clear and definite & $\begin{array}{l}\text { Complexity } \\
\text { diverse }\end{array}$ & Unified and strict & Advanced and norm \\
\hline Evaluation cycle & $6-7$ years & 2 years & $4-5$ years & $4-5$ years \\
\hline Evaluation result & $\begin{array}{l}\text { link up with allocate funds } \\
\text { directly }\end{array}$ & $\begin{array}{l}\text { Be irrelevant } \\
\text { allocate funds }\end{array}$ & $\begin{array}{l}\text { link up with allocate funds } \\
\text { directly }\end{array}$ & $\begin{array}{l}\text { link up with allocate } \\
\text { funds indirectly }\end{array}$ \\
\hline
\end{tabular}




\section{Chinese Characteristics and International Standards: A Basic Approach to Design of Evaluation System for Scientific and Technological Innovation Capability}

\subsection{New Connotation of "Double First-Class" Universities' Scientific and Technological Innovation Capability Dimension}

Internationally, the knowledge innovation in western developed countries relies mainly on universities and research centers for research output, taking knowledge as a hub, the special form of bringing economic interests to the countries and the regions is often understood as the scientific and technological innovation capability of institutions and universities in the west. consequently, from the prospect of international development trend of scientific research evaluation of developed countries in the world, scientific and technological innovation capability primarily lies in "the benefit and influence of scientific research output", namely the actual influence to a country and a region under the premise of adhering to the goal of "academic excellence" and to measure overall scientific and technological innovation capability of universities according to "input and output "evaluation model, the impact of a country and a region will be enormous especially when high-level scientific research achievements of the most "original innovation "appears. Therefore, university's general level, capacity、 quality and efficiency of providing "social services" for country and world to fulfill its third social mission "should be more highlighted in the "scientific and technological innovation capability" in the process of building "Double First-Class" universities in China(Xia, 2013). Scientific and technological innovation capability of colleges and universities can be divided into the productive capacity of and transformative capability in order to measure it. Therefore, comprehensively considering the dimension of evaluation content that developed countries in the world used in evaluating their own "scientific and technological innovation capability", the scientific and technological capability of "Double First-Class" university can be structurally summarized into four main aspects: its investment capacity of university science and technology innovation, its productive capacity and transformative capability of new scientific and technological achievements, its supportive capacity of scientific and technological innovation and its collaborative innovation capability in integrating innovation factors.

\subsection{The index design should reflect international development trend and Chinese cultural characteristics}

Core elements of "world-class" universities mainly include: cultivating outstanding talents, internationally influential subjects and achievements, and influential teachers.

Thus the evaluation index of "Double First-Class "universities' scientific and technological innovation capability should emphasize and reflect the common features of world-class universities, such as world-class students, the academic elite, first-class achievements, international reputation, first-class service. At the same time, each of the world's leading universities should have distinctive features, which are crucial to the construction of world-class universities. Distinctive universities are not necessarily "world-class" universities, but world-class universities must have their own characteristics. For this reason, "characteristic development indicators" should be established in evaluation indexes to reflect its comprehensiveness and individuation difference. The local Chinese cultural features intensively reflect the demands of "difference" and "individuation" in the construction of "Double First-Class" universities in China. The index design of "local cultural characteristics" of China's scientific and technological innovation capability can be reflected in the following aspects:

Firstly, the evaluation index of the scientific research innovation ability of China's "Double First-Class" universities should reflect "cultural characteristics" and "historical deposits" of Chinese universities.

"The heritage and reputation is more important for universities, good universities in the people's mind cannot be assessed with monotonous indicators." President Jinping Xi said. Therefore, the universities' scientific research evaluation index that reflects China's "cultural characteristics" and "history deposits" should not blindly pursue the external university scientific research evaluation index of "world-class universities but establish the "internal standard" of Chinese universities in the process of self-development and self-construction. Because the "Double First-Class" is not blindly to follow the "world-class" of developed countries, it is "world-class" with Chinese characteristics, this is the due meaning and value standard of how to evaluate the scientific and technological innovation capability of China's "world-class universities" in the process of "Double First-Class" construction.

Secondly, the evaluation index of scientific and technological innovation ability of Chinese "Double First-Class" university should be designed to depend on the "world standard", but it should more reflect the fundamental value orientation and practice standard of scientific research evaluation of Chinese universities.

For one thing, the scientific research evaluation of "Double First-Class" university should have an international vision and actively integrate the global development trend, but it should also put forward the criteria that meet 
China's actual condition. At present, the evaluation result of "technological innovation capability" will be affected by the loss of international competitiveness. Chinese scholars' world influence is largely based on the "authoritative academic discourse system" of the developed countries of the U.S. and the UK, which rarely reflected Chinese scholars' cultural characteristics and value orientation under the context with the English as a main language, especially for the social science researchers, the impact and contribution to the world is not enough, which led to some certain effect on evaluation result of "technological innovation capability "because of the loss of international competitiveness. So, establishing and forming the evaluation index that reflects the discourse system with Chinese cultural value is the important dimension and evaluation standard to measure the scientific and technological innovation capability of "Double First-Class "universities in China. Professor Li Jun, at the university of Hong Kong, has proposed that the Chinese university 3.0 model is of great significance to balance the global, regional and local mission of the university, and points out that Chinese universities are summarized with the four core values and features: college autonomy, freedom of thought, the humanistic mission of uniting the knowledge and action, and the variety of harmony in diversity $(\mathrm{Li}, 2016)$, which reflects the difference in development model between Chinese and British universities and shows that the Chinese value orientation of scientific and technological innovation capability evaluation should focus on establishing corresponding indicators in the process of the construction of "Double First-Class".

For another thing, the "practice orientation" should be insisted in the scientific research evaluation standards of Chinese universities. Because the evaluation goal multivariate basically determines the value orientation, it ultimately affects the "practice orientation" of scientific evaluation, which means that the index design should pay more attention to actual "evaluation purpose "of scientific research, and examine systematically successful reform and practical experience of Chinese universities in process of constructing world class universities and their future role in developing and promoting world civilization, constructing modern university system with Chinese characteristics and launching a global dialogue.

\subsection{The Evaluation System Adopts Differentiated Design and Establishes Classified Evaluation Standard}

The evaluation system of "Double First-Class" university's scientific and technological innovation capability should be different for different types of colleges and universities in "index design" and "weight system", and show the difference and individuation of science and technology innovation capability in different universities. Difference and individuation can create harmony in diversity and show different beauty in the process of constructing "Double First-Class" universities, which influence and enrich the diversity of evaluation criteria of the development model of "world First-class" universities, so that colleges and universities can realize the real meaning of "one school one evaluation" rather than "thousand schools one evaluation" in the evaluation of standard practice orientation. For example, for engineering universities, the scientific research evaluation system should concentrate on the contribution of academic research to national economic and social development and increase the proportion and weight of application and development research, the technological innovation, transformation and its economic and social benefits should be emphasized and the third-party evaluation mechanism with multiple participates of government, enterprise, industry should be established, besides, the introduction of the international first-class talents and students' practical application and operation ability should be also focused on; The "Double First-Class" universities based on the humanities and social sciences should evaluate the inheritance and realization of humanistic values and the historical role of promoting the integration of world civilization. Therefore, the different universities have different evaluation criteria, and it should avoid using a standard system to evaluate universities of different types and development levels.

\subsection{Evaluation System Construction Should Reflect Multi-Dimensional Evaluation Content}

At present, global university rank has formed the "Specialization" systematically supervision and dominates the systemic reconstruction of the higher education $(\mathrm{Li}, 2017)$. The scientific research evaluation index system which was led by development model of the universities in England and the United States has always conducted and affected the basic way of the construction of universities in developing countries. The global rank and scientific research evaluation provides a reference pedigree to promote the scientific research level of "first-class" universities, but it is vital that the quantitative criteria of excessive research achievements exert a serious negative impact on academic life, because no one can avoid the control of "standardization", "commercialization" and "homogeneity" $(\mathrm{Li}, 2017)$. As a result, it is necessary to construct multi-dimensional and multivariate evaluation contents to reflect the nature of scientific research evaluation and to fully consider the "ecological" and "healthy" as well as "sustainable development" of scientific research evaluation system in the construction of scientific research evaluation system of "Double First-Class" university in China. Therefore, it provides turning points and opportunities for the development of a world-class scientific evaluation system with Chinese characteristics. For example, reflecting new output dimension of scientific and technological 
achievements, scientific research environment, scientific research application and other dimensions can be considered the dimensions of scientific research achievements to realize the overall optimization of scientific research ecology, naturally it will form a virtuous cycle of scientific research environment, scientific research output and scientific research application. In terms of design, evaluation dimensions and specific indicators, we can consider the following interconnections and complementary factors: subjective and objective, input and output, process and results, as well as effectively improve the benign development of scientific research level through completely scientific evaluation and monitoring of scientific research activities.

\section{Acknowledgments}

This paper is funded by the following projects:The People's Republic of China Ministry of Education Humanities and Social Science Research Youth Fund Projects "Innovative Talents of Science and Technology Academic Entrepreneurship Ability Structure and Cultivation Mechanism Research" (Project Number: 15YJC880024) and Social Sciences Planning Project in Jiangxi Province "Innovative Talents of Science and Technology Academic Entrepreneurship Ability Structure and Cultivation Mechanism Research in Jiangxi Province " (Project Number: 15JY06) and Jiangxi Provincial Educational Reform project "Practice Exploration on Training Mode of Top Innovative Scientific and Technological Talents Based on Five Factors Quality Structure Model-A Case Study of Universities in Jiangxi Province" (Project Number: jxjg-16-24)

\section{References}

Aldo, G., \& Ben, R. M. (2003). University Research Evaluation and Funding: An International Comparison. Minerva: A Review of Science, Learning and Policy, 41(4), 277-304. https://doi.org/10.1023/B:MINE.0000005155.70870.bd

Australian Research Council. (2012). Excellence in Research for Australia 2012[EB/OL]. Retrieved from http://www.arc.gov.au/pdf/era12/report_2012/ARC_ERA12_Introduction.pdf.2012-01-03/2013-04-07

Australian Research Council. (2018). Gender and the Research Workforce-Excellence in Research for Australia (ERA). Retrieved from https://www.arc.gov.au/policies-strategies/policy/corporate-plan.

Australian Research Council (2012). ERA 2012 Evaluation Handbook. Canberra: Australian Research Council, $10-25$.

Berkeley Center for Teaching \& Learning. Retrieved from http://Teaching.Berkeley.edu/academic-programs

Chen, N. (2007). Evaluation and evaluation of scientific and technological evaluation in the United States. Global science and technology economy, 12, 25-31.

Documentation Francaise. Documentation on the New Law on budgeting [EB/OL]. Retrieved from http://www.ladocfrancaise.gouv.fr/dossier_actualite/constitution_financiere/index.shtml

Huang, X. P., \& Chen, Y. Z. (2017). Evaluation of Science and Technology Innovation Ability of "Double First-Class" University: International Experience and Enlightenment-Based on Investigation of Evaluation System of British, French, American and Australian research. Jiangsu High Education, 1, 93-98.

Kan, Y. (2010). Research on Performance Evaluation of Higher Education in Modern Britain. Beijing: Higher Education Press, pp. 187.

Li, J. (2016). Chinese University 3.0 Model -- Tradition, Modernity and Foresight. Tsinghua University Education Research, 7, 24-35.

Li, J. (2017). Global University Rankings, Scientific Evaluation and Higher Education Reconstruction-Comparison between Mainland China, Hong Kong and Japan. Higher Education Research, $6,1-11$.

National Research Council (2004). Assessing Research Doctorate Programs: A Methodology Study. Washington DC: National Academies Press, 4, 22.

Ryuohtani, M. K., \& Naoto, K. (2013). An Introduction to the Research Excellence Framework: A new research evaluation framework for universities in the UK. Synthesiology, 9, 121-126.

Sue, H. (2015). 2014 Research Excellence Framework. Social Policy Section, 18(12), 8.

Tony, M., \& Daniel, S. (2014). Perceptions of the UK's Research Excellence Framework 2014: A Media Analysis. Journal of Higher Education Policy and Management, 6, 603-615. https://doi.org/10.1080/1360080X.2014.957890

Xiang, Y. L. (2016). "Double-Class" Construction: Myth, BP and Localization. Modern Education Management, 
$10,12-17$.

Xia, Q. H. (2013). Academic Entrepreneurship: the Cognition and Implementation Mechanism of China's Research "Third Mission". Wuhan University Press.

Zhang, Q. S. (2016). Evaluation of Chinese universities in the Perspective of "Double First-Class" Construction. Chongqing High Education Research, 2, 126-127.

\section{Copyrights}

Copyright for this article is retained by the author(s), with first publication rights granted to the journal.

This is an open-access article distributed under the terms and conditions of the Creative Commons Attribution license (http://creativecommons.org/licenses/by/4.0/). 